\title{
Gender Differences in Alcohol Choice among Russians: Evidence from a Quantitative Study
}

\author{
Yuka Minagawa \\ Department of Sociology and Population Research Center, The University of Texas, Austin, Tex., USA; Advanced \\ Research Institute for the Sciences and Humanities, Nihon University, Tokyo, Japan
}

\section{Key Words}

Alcohol use - Gender differences - Health situation •

Mortality $\cdot$ Russian Federation

\begin{abstract}
Aims: Qualitative studies find that men and women in Russia have different preferences for alcoholic beverages, but quantitative evidence for gender differences in beverage type choice remains scarce. The purpose of this article is to test numerically whether and to what extent men and women in Russia differ in terms of preferences for type of drink, such as vodka, wine and beer. Methods: Results are based on multinomial logistic regression and ordinary least squares regression analyses of the Russian Longitudinal Monitoring Survey-Higher School of Economics 2008 data. Results: We observed significant gender differences in preferences for alcoholic beverages. Men have strong preferences for vodka, and they drink it in much larger amounts in comparison with women. Women are more likely to either refrain from drinking or drink mild types of alcoholic beverages, such as wine and beer. Gender differences remain statistically significant even when sociodemographic factors are well accounted for. Conclusions: The present study confirms the previous research findings about gender differences in drinking practices among Russians. Our results provide quantitative evidence of the pronounced differences in beverage types consumed by men and women.

Copyright $\odot 2012$ S. Karger AG, Basel
\end{abstract}

\section{Introduction}

The disintegration of the Soviet Union in 1991 had devastating consequences on population health [1]. The transition process away from Communism caused a significant decline in basic socioeconomic conditions, produced tremendous stress among individuals and adversely affected their physical as well as psychological wellbeing $[2,3]$. All the former Soviet republics reported a decline in life expectancy at birth during the first half of the 1990s, but none was as large as in Russia. The ageadjusted mortality rate rose by 39\% between 1990 and 1994, and life expectancy at birth dropped by 6.03 years for men and 5.18 years for women during the same period [4]. One point to note is that, while the collapse of the Soviet Union had enormous implications for all citizens in the country, the health consequences of this historic event appear to differ by gender. It is men, particularly working-aged men, who have faced extreme disadvantages in terms of longevity. The death rate for men aged 35-44 years almost doubled between 1990 and 1994 [4], and large gender differences in longevity still persist in the country. Today, Russia has one of the largest gender gaps in life expectancy at birth in the world $[5,6]$.

A great deal of research implicates negative health behaviors among Russian men as a major contributor to premature male mortality [5, 7-10]. Russian men's health lifestyles feature excessive drinking, heavy smoking and

\section{KARGER}

Fax +4161306 1234

E-Mail karger@karger.ch

www.karger.com (c) 2012 S. Karger AG, Basel

$1022-6877 / 13 / 0192-0082 \$ 38.00 / 0$

Accessible online at:

www.karger.com/ear
Yuka Minagawa

Department of Sociology and Population Research Center, The University of Texas 110 Inner Campus Drive Stop G1800

Austin, TX 78712 (USA)

E-Mailyminagawa@utexas.edu 
a lack of physical exercise [5]. In particular, alcohol has been suggested as a major determinant of male mortality [11-16]. Alcohol-related causes, such as cardiovascular disease, alcohol poisoning and accidents, characterize Russian men's mortality profile $[4,16,17]$. There is increasing evidence of large gender differences in drinking behavior among Russians. Males in Russia are less often nondrinkers $[9,13,18]$, have higher levels of alcohol intake per occasion $[9,13,19]$ and are more likely to engage in binge drinking $[12,13]$ compared to their female counterparts. Alcohol-related problems in life are common among men [12]. These observations suggest that alcohol consumption has an important bearing on Russian men's health disadvantages, thereby contributing to the large gender gap in longevity $[9,13]$.

However, missing from most of these studies is an attention to beverage types consumed by men and women. Many studies tend to focus on differences in frequency or the average amount consumed per occasion $[11,13]$. Some studies pay attention to the type of alcohol consumed by individuals, but they often use the amount of specific beverages, such as vodka, beer and wine, as a default $[6$, $19,20]$, neglecting dynamics behind the decision making process regarding the individual's choice of beverage type. In fact, it is of particular importance to focus on beverage types in the Russian context, because most alcohol in Russia is consumed in a specific form of spirits, that is vodka [21]. Vodka is diminutive of the word 'voda', which means water in Russian, and, literally, it has been 'living water' for Russians [22]. Findings from qualitative studies elucidate that drink preferences might differ by gender; men tend to drink vodka, whereas wine and beer are more popular among women $[13,23]$. These research findings indicate substantial differences not only in terms of 'how' men and women drink alcohol, but also in 'what' they consume. However, no quantitative study has yet numerically tested gender differences in beverage type choice. Gender differences in alcohol choice have been more or less taken for granted. Several important issues consequently remain to be explored: To what extent do men and women differ in terms of the alcoholic beverages they consume? Are gender differences in alcohol choice significant even when sociodemographic factors are accounted for? Do we observe similar patterns in the volume of consumption as well?

The purpose of the present study is to investigate drinking behavior among men and women in Russia, with particular attention given to beverage type choice. This research departs from previous studies by specifically focusing on differences in beverage types that are consumed by men and women. By doing so, the present study provides a more comprehensive and detailed picture of drinking practices among Russians and offers insights into the potential mechanisms underlying the large gender gap in health and mortality.

\section{Methods}

The data for this study come from the Russian Longitudinal Monitoring Survey of the Higher School of Economics (RLMSHSE). The RLMS-HSE is a household-based survey designed to monitor the socioeconomic conditions of the population, using interview-administered questionnaires, and it is representative of all noninstitutionalized individuals living in households in the Russian Federation [24]. In this study, we used data from Round 17, collected between September and December 2008. We limit the analysis to respondents aged 18 and older, reflecting the legal age for drinking in Russia. Individuals with missing data on variables of interest were excluded from the analyses, which resulted in a total of 7,937 individuals (male $=3,724$, female $=4,213$ ) for the final study sample.

Self-reported alcohol consumption was the primary outcome variable. The alcohol use index was based on the following 3 questions: (1) 'In the last 30 days, have you consumed alcoholic beverages?'; (2) 'Which of these beverages did you drink in the last 30 days?', and (3) 'For those who drank, how many grams did you usually drink per day?'. Response categories to question 2 were 'beer', 'home-brewed beer', 'dry wine, champagne', 'fortified wine', 'homemade liquor', 'vodka or other hard liquor', 'alcohol cocktails' and 'anything else'. Based on this information, we created alcohol categories and volume of consumption variables (table 1). First, based on answers to questions 1 and 2, we created 3 categories of alcohol consumption: no alcohol use, vodka and other alcohol (e.g. beer, wine and cocktails). If respondents answered 'no' to question 1 , they were considered nondrinkers (i.e. the 'no alcohol use' category). Also, we classified those who reported vodka and hard liquor consumption in the 'vodka' category, even if they also consumed other types of alcoholic beverages. Second, in order to measure the volume of consumption, we created variables for daily consumption levels for three kinds of beverages, i.e. vodka, beer and wine (dry wine, champagne and fortified wine combined). Since only a limited number of respondents reported the volume of cocktail consumption (in total 338 people), we excluded the level of cocktail consumption from the analysis.

The major predictor variable was gender. It was coded as male or female (the referent). Given that alcohol consumption is closely associated with individuals' sociodemographic characteristics [9], a number of covariates were included in the analyses. Age was scored as the number of years. Employment status was coded 1 if the respondent was currently working full- or part-time and 0 otherwise. Income was assessed using a question that asks the total amount of money that the respondents received in the last 30 days. Due to the skewed distribution, we logarithmically transformed this variable. Education was measured here in a dichotomous fashion: 1 = less than high school or high school, $0=$ otherwise. Marital status was coded 1 for currently married and 0 otherwise. Additionally, since Russians who consume alcoholic beverages are also more likely to smoke [10], we tested the effect 
Table 1. Definitions of alcohol categories and volume of consumption

\begin{tabular}{|c|c|}
\hline Item & Definition \\
\hline \multicolumn{2}{|l|}{ Alcohol category } \\
\hline No alcohol use & drank no alcoholic beverages in the last 30 days before the study \\
\hline Vodka & drank vodka or other hard liquor \\
\hline Other alcohol & $\begin{array}{l}\text { drank only beer, home-brewed beer, dry wine, champagne, fortified wine, homemade } \\
\text { liquor or cocktails }\end{array}$ \\
\hline \multicolumn{2}{|c|}{ Volume of consumption } \\
\hline Vodka & grams of vodka or other hard liquor per day \\
\hline Beer & grams of beer or home-brewed beer per day \\
\hline Wine & grams of dry wine, champagne or fortified wine per day \\
\hline
\end{tabular}

Table 2. Distribution of variables by gender (RLMS-HSE, 2008)

\begin{tabular}{llll}
\hline Variable & $\begin{array}{l}\text { Males } \\
(\mathrm{n}=3,724)\end{array}$ & $\begin{array}{l}\text { Females } \\
(\mathrm{n}=4,213)\end{array}$ & p value \\
\hline $\begin{array}{l}\text { Alcohol use } \\
\text { Type }\end{array}$ & & & \\
$\quad$ Do not drink alcohol, \% & $15(572)$ & $28(1,183)$ & $<0.001$ \\
$\quad$ Drink vodka, \% & $57(2,116)$ & $27(1,137)$ & $<0.001$ \\
$\quad$ Drink other alcohol, \% & $28(1,036)$ & $45(1,893)$ & $<0.001$ \\
Volume & $291.84(243.41)$ & $168.66(110.58)$ & $<0.001$ \\
$\quad$ Grams of vodka & $975.44(732.39)$ & $620.96(470.13)$ & $<0.001$ \\
$\quad$ Grams of beer/home-brewed beer & $385.54(325.93)$ & $250.73(177.87)$ & $<0.001$ \\
$\quad$ Grams of dry/fortified wine/champagne & & & $<0.001$ \\
Sociodemographic characteristics & $41.59(15.85)$ & $43.22(16.33)$ & $<0.001$ \\
Age, years & $43(1,584)$ & $32(1,364)$ & 0.003 \\
Less than high school education, \% & $70(2,604)$ & $67(2,813)$ & $<0.001$ \\
Currently working, \% & $9.25(0.81)$ & $8.97(0.80)$ & $<0.001$ \\
Income (logged) & $61(2,260)$ & $49(2,057)$ & $<0.001$ \\
Married, \% & $10.95(10)$ & $2.51(5.54)$ & \\
Cigarette use, n/day & & & \\
\hline
\end{tabular}

Values represent percentages (absolute numbers) for categorical variables and means (standard deviations) for continuous variables. p values summarize statistical significance for differences between males and females.

of smoking. Cigarette smoking was measured by the number of cigarettes consumed by the respondents per day.

We used multinomial logistic regression and ordinary least squares regression models to examine how drinking practices vary by gender in terms of beverage type and volume. The analysis had two parts. The first part examined gender differences in alcohol choice, focusing on the three categories of no alcohol use, vodka and other alcohol. This model used 'no alcohol use' as the reference category and estimated the odds that individuals either choose vodka or other types of alcohol as opposed to refraining from drinking. Given the large number of respondents who indicated no alcohol intake in the last 30 days before the study, we included the category of no alcohol use into the analysis. The second part of the analysis examined the volume of alcohol con- sumption, using the self-reported amount (grams per day) of vod$\mathrm{ka}$, beer and wine as dependent variables. There were two statistical models. The first model contained only gender and age. The second model added measures of sociodemographic characteristics. Also, we included the number of cigarettes consumed into all the models as a control variable.

\section{Results}

Table 2 presents percentages, means and standard deviations for all variables included in the analysis. The distribution of the outcome variable, i.e. alcohol consump- 
Table 3. Multinomial logistic regression models for beverage type choice (RLMS-HSE, 2008; $\mathrm{n}=7,937$ )

\begin{tabular}{|c|c|c|c|c|}
\hline & \multicolumn{2}{|l|}{ Model 1} & \multicolumn{2}{|l|}{ Model 2} \\
\hline & $\begin{array}{l}\text { vodka vs. } \\
\text { no alcohol }\end{array}$ & $\begin{array}{l}\text { other alcohol vs. } \\
\text { no alcohol }\end{array}$ & $\begin{array}{l}\text { vodka vs. } \\
\text { no alcohol }\end{array}$ & $\begin{array}{l}\text { other alcohol vs. } \\
\text { no alcohol }\end{array}$ \\
\hline Male & $2.69(0.19)^{* * *}$ & $0.92(0.07)$ & $2.48(0.18)^{* * *}$ & $0.90(0.07)$ \\
\hline Age & $1.00(0.01)$ & $0.97(0.02)^{* * *}$ & $1.01(0.02)^{* * *}$ & $0.98(0.02)^{* * *}$ \\
\hline Less than high school education & & & $0.97(0.06)$ & $0.92(0.06)$ \\
\hline Currently working & & & $1.56(0.12)^{* * *}$ & $1.15(0.09)$ \\
\hline Income (logged) & & & $1.36(0.06)^{* * *}$ & $1.18(0.05)^{* * *}$ \\
\hline Married & & & $1.07(0.07)$ & $0.93(0.06)$ \\
\hline Cigarette use & $1.05(0.04)^{* * *}$ & $1.02(0.05)^{* * *}$ & $1.05(0.05)^{* * *}$ & $1.02(0.01)^{* * *}$ \\
\hline
\end{tabular}

Table 4. Ordinary least squares regression models for volume (grams) of alcohol consumption by beverage type (RLMS-HSE, 2008)

\begin{tabular}{lccc}
\hline & Vodka & Beer & Wine \\
\hline Male & $99.83(8.36)^{* * * *}$ & $253.97(23.49)^{* * *}$ & $95.24(12.08)^{* * * *}$ \\
Age & $-1.09(0.27)^{* * * *}$ & $-5.16(0.79)^{* * * *}$ & $-1.68(0.32)^{* * *}$ \\
Less than high school education & $9.69(7.46)$ & $69.46(21.36)^{* * *}$ & $17.14(10.74)$ \\
Currently working & $-11.20(9.55)$ & $10.66(26.71)$ & $-3.54(12.49)$ \\
Income (logged) & $-8.16(5.20)$ & $22.84(13.65)$ & $13.04(6.47)^{*}$ \\
Married & $-14.41(7.55)$ & $-42.62(21.73)$ & $-7.14(9.75)$ \\
Cigarette use & $3.20(0.39)^{* * *}$ & $12.57(1.17)^{* * *}$ & $4.80(0.70)^{* * *}$ \\
Constant & 290.89 & 540.37 & 192.29 \\
Adjusted $\mathrm{R}^{2}$ & 0.11 & 0.12 & 0.10 \\
$\mathrm{n}$ & 3,248 & 3,732 & 2,163 \\
\hline
\end{tabular}

Values in parentheses represent standard errors. ${ }^{\star} \mathrm{p}<0.05 ;{ }^{* *} \mathrm{p}<0.001$.

tion, demonstrates clear gender differences in drinking practices in terms of choice as well as volume. Vodka consumption is much more prevalent among men than among women; $57 \%$ of male respondents had consumed vodka or other hard liquor in the last 30 days before the survey, while $27 \%$ of females had. A similar result was found for volume. Men have a much higher mean volume of vodka consumption than women. Concerning alcoholic beverages other than vodka, women tend to consume other alcohols, namely wine and beer, but men drink these beverages in much larger amounts. Also, descriptive statistics show that women are more likely to refrain from alcohol consumption compared to men.

Table 3 presents multinomial logistic regression analyses predicting alcohol choice among men and women in Russia. The results show strikingly different patterns of beverage type choice by gender. In short, men in Russia have strong preferences for vodka. Model 1 shows that men have $169 \%$ higher odds of drinking vodka than women over the past month, controlling for age and the number of cigarettes [odds ratio (OR) 2.69; $\mathrm{p}<0.001$ ]. On the other hand, when the comparison is between drinking other types of alcoholic beverages (e.g. beer and wine) or refraining from drinking, drinking behavior does not differ greatly between men and women. Men exhibit $8 \%$ lower odds of drinking wine or beer than women (OR 0.92), but the result is not significant at the 0.05 level.

Model 2 in table 3 presents differences in alcohol choice between men and women after adjusting for age, 
socioeconomic factors and cigarette use. The inclusion of these factors in model 2 slightly reduces men's odds of drinking vodka (OR reduced from 2.69 to 2.48), but the gender difference in alcohol choice remains statistically significant at the 0.001 level. Men exhibit more than twice the odds of choosing vodka in comparison with women, net of all controls. Thus, gender differences in vodka consumption are not explained by differences in sociodemographic factors between men and women. Further, controlling for educational attainment, employment status, income and marital status produces no appreciable change in gender differences in drinking other types of alcoholic beverages relative to no alcohol use (OR reduced from 0.92 to 0.90 ).

We also looked at the effects of sociodemographic factors on beverage type choice (model 2). Age is related to higher odds of drinking vodka $(\mathrm{OR}=1.01)$, but it is related to lower odds of drinking other types of alcoholic beverages $(\mathrm{OR}=0.98)$. Being employed is strongly related to higher odds of vodka consumption among Russians, but employment status is not associated with odds of drinking other alcoholic beverages relative to refraining from drinking. Also, high income is related to overall alcohol consumption. Consistent with prior research [10], cigarette use was associated with increased odds of alcohol consumption throughout the analysis $(\mathrm{p}<0.001)$.

Next, we examined gender differences in the volume of alcohol consumption. Table 4 presents the results from ordinary least squares regression models, using grams of vodka, beer and wine as dependent variables. For brevity, only the results of the full model are shown. Two important findings emerge. First, we observed clear gender differences in the volume of vodka consumption. Men drink $99.83 \mathrm{~g}$ more of vodka than women on average, net of all controls. This pattern suggests that men are apt not only to choose vodka in lieu of other alcoholic beverages but also to drink it in much larger amounts than women. Second, the levels of beer and wine consumption were much higher among men than among women. Men drink $253.97 \mathrm{~g}$ more of beer and $95.24 \mathrm{~g}$ more of wine than women per day on average, when the sociodemographic characteristics are held constant. All these results are statistically significant at the 0.001 level. Overall, a comparison of the results in tables 3 and 4 leads to an interesting finding. Although men appear to have a strong preference for drinking vodka, when they choose beer and wine, they drink these beverages in much larger amounts compared to women.

\section{Discussion}

There is compelling evidence for large differences in drinking behavior between men and women in Russia. While studies focusing on differences in the frequency or the volume of consumption abound, few researchers to date have investigated how the preferences for alcoholic beverages differ by gender. Qualitative studies find that men and women in Russia tend to consume different kinds of alcohol, but quantitative research on this topic remains scarce. Using recent nationally representative data, the present study numerically tests gender differences in drinking behavior in terms of choice and volume, with a special focus on vodka, beer and wine.

The results of the present study suggest a number of intriguing conclusions. First, Russian men tend to choose vodka out of many other alcoholic beverages. Men exhibit much higher odds of drinking vodka than women, and these differences are not explained by sociodemographic factors. In contrast, women tend to refrain from drinking or to choose mild types of alcohol rather than drinking vodka. Second, men exceed women in the volume of alcohol consumption across all beverage types. In particular, men drink much larger amounts of vodka than women, again confirming Russian men's inclination toward vodka consumption. Additionally, although men do not exhibit strong preferences for wine and beer, when they drink these beverages, their consumption levels are much higher than those of women. These results confirm previous research findings regarding gender differences in drink preferences. Russian men have strong preferences for vodka, and they drink larger amounts of alcohol than their female counterparts regardless of type.

In fact, clear differences in beverage type choice shed some light on the potential mechanisms underlying the gender gap in mortality in contemporary Russia. Men's drinking patterns, characterized by high levels of vodka consumption, appear to have detrimental effects on their health, while refraining from alcohol use or drinking mild types of alcohol protects women from the drastic decline in health status [9]. Evidence suggests that the effect of alcohol on the risk of cardiovascular disease largely depends on the type of drink [25]. Klatsky and Armstrong [26], for example, report that coronary heart disease risks are highest among hard liquor drinkers and lowest among wine drinkers. It has been suggested that regular consumption of beverages with low alcohol content, as often seen in wine consumption among Europeans, protects individuals from heart disease [27]. In the 
case of Russia, however, due to men's considerable preferences for vodka and other strong spirits [15], the association between drinking and mortality seems to be linear, indicating that there is no $\mathrm{U}$ or $\mathrm{J}$ curve as often reported in Western countries [28]. Taken as a whole, these observations highlight the importance of focusing on beverage types that are respectively consumed by men and women to better understand the relationship between alcohol consumption and physical health outcomes in the Russian context.

What could explain the distinct differences in alcohol choice between men and women in Russia? Gender roles are the key to answering this question. Gender differences in alcohol use often reflect how societies symbolize and regulate male and female roles, and thus drinking behavior is largely influenced by sociocultural norms and customs associated with gender roles $[29,30]$. In the case of Russia, alcohol consumption, particularly vodka, is closely related to male roles in society. Vodka consumption originated in a rural peasant culture, but upon the establishment of the Soviet Union, it was removed from rural traditions and extended into the Soviet-style mechanized culture, as heavy industrialization transformed peasants into industrial workers $[5,19]$. As a result, vodka became an important part of Russian men's working culture. Drinking with colleagues is a key element of socialization, which often involves alcohol, namely vodka, among Russian men. On the other hand, women's jobs were limited to the home, which hardly left them free time for drinks after work [13, 31]. Overall, in contrast to many countries in the world, drinking alcohol is by no means a social stigma in Russia, particularly for men. Rather, alcohol consumption is a social norm related to male roles as industrial workers or breadwinners, but such behavior is not culturally accepted for women [5].

This research has several strengths, including the use of the large nationwide sample of Russians, the use of recent data from 2008 and the statistical analysis of drinking behavior in men and women. However, our results should be interpreted in light of the study's limitations. First, we suspect that the measurement of alcohol use is subject to underestimation. It has been suggested that the alcohol measures in the RLMS-HSE sample are not accurate estimates of the actual alcohol consumption level in the country [32]. Therefore, appropriate caution must be exercised in interpreting results from this study. Second, this study uses 'no alcohol use' as the basis for comparison. In the present study, $15 \%$ of men and $28 \%$ of women in the sample indicated no al- cohol consumption. One of the potential explanations for the high rates of nondrinkers is age. Since alcohol consumption generally declines with age, the presence of the elderly in the current study may increase the proportion of those who refrained from alcohol use. To address the issue, we limited the sample to individuals between 18 and 60 years of age, but the substantive conclusions remain the same regardless of the age group. Finally, this study, like other cross-sectional investigations, cannot be definitive in its conclusion. Changes in alcohol policy or availability of alcohol, for instance, may have temporal influences on drinking levels in a given country [33]. In light of the severity of the problem, the Russian government has indeed taken legal measures to restrict the sale of alcoholic beverages in the country [21]. While the overall level of consumption may fluctuate due to broader social circumstances, distinct preferences for alcohol beverages by gender are one of the most consistent findings in studies on alcohol in Russia, which strengthens our confidence in the validity of the present findings.

This study's results, together with its strengths and weaknesses, suggest an important direction for future research. Twenty years have passed since the collapse of the Soviet Union, and Russian society has been through drastic transformations over that time. For example, evidence suggests that alcohol use is becoming more popular among women [20]. Today, women in Russia seek a break with the Soviet past through alcohol consumption, and the ideal of Western masculinity associated with independence and assertiveness encourages such behavior [34]. Will such increases in alcohol use deteriorate women's health, and consequently, are we going to observe the convergence of health outcomes between men and women in Russia? To answer these questions, continued thorough research on drinking behavior among Russians is needed.

\section{Acknowledgement}

We thank the RLMS Phase 2, funded by the USAID and NIH (R01-HD38700), Higher School of Economics and Pension Fund of Russia, and the Carolina Population Center and Russian Institute of Sociology for making these data available. An earlier draft of this paper was presented at the 2011 anunal meeting of the Population Association of America (PAA), Washington, DC. 


\section{References}

1 Cornia GA, Paniccia R: The demographic impact of sudden impoverishment: Eastern Europe during the 1989-94 transition. Innocenti Occasional Papers Economic Policy Series. Florence, The United Nations Children's Fund, 1995.

-2 Rosefielde S: Premature deaths: Russia’s radical economic transition in Soviet perspective. Eur Asia Stud 2001;53:1159-1176.

>3 Poznyak VB, Pelipas VE, Vievski AN, Miroshnichenko L: Illicit drug use and its health consequences in Belarus, Russian Federation and Ukraine: impact of transition. Eu Addict Res 2002;8:184-189.

4 Notzon FC, Komarov YM, Ermakov SP, Sempos CT, Marks JS, Sempos EV: Causes of declining life expectancy in Russia. JAMA 1998;279:793-800

5 Cockerham WC: Health lifestyles in Russia. Soc Sci Med 2000;51:1313-1324

-6 Cockerham WC, Hinote BP, Cockerham GB, Abbott P: Health lifestyles and political ideology in Belarus, Russia, and Ukraine. Soc Sci Med 2006;62:1799-1809.

$\checkmark 7$ Cockerham WC: The social determinants of the decline of life expectancy in Russia and Eastern Europe: a lifestyle explanation. J Health Soc Behav 1997;38:131-148.

8 Leon DA, Shkolnikov VM: Social stress and the Russian mortality crisis. JAMA 1998; 270:790-791

$\checkmark 9$ Leon DA, Shkolnikov VM, McKee M: Alcohol and Russian mortality: a continuing crisis. Addiction 2009; 104:1630-1636.

$\checkmark 10$ McKee M, Bobak M, Rose R, Shkolnikov VM, Chenet L: Patterns of smoking in Russia. Tob Control 1998;7:22-26.

11 Bobak M, McKee M, Rose R, Marmot M: Alcohol consumption in a national sample of the Russian population. Addiction 1999;94: 857-866.

12 Bobak M, Room R, Pikhart H, Kubinova R, Malyutina S, Pajak A, Kurilovitch S, Topor R, Nikitin Y, Marmot M: Contribution of drinking patterns to differences in rates of alcohol related problems between three urban populations. J Epidemiol Community Health 2004;58:238-242.
13 Bobrova N, West R, Malyutina D, Malyutina S, Bobak M: Gender differences in drinking practices in middle aged and older Russians. Alcohol Alcohol 2010;45:573-580.

14 Leon DA, Chenet L: Huge variation in Russian mortality rates 1984-94: artefact, alcohol, or what? Lancet 1997;350:383-388

15 Pomerleau J, McKee M, Rose R, Haerpfer CW, Rotman D, Tumanov S: Hazardous alcohol drinking in the former Soviet Union: a cross-sectional study of eight countries. Alcohol Alcohol 2008;43:351-359.

16 Shkolnikov V, McKee M, Leon DA: Changes in life expectancy in Russia in the mid-1990s Lancet 2001;357:917-921.

17 Brainerd E, Cutler DM: Autopsy on an empire: understanding mortality in Russia and the former Soviet Union. J Econ Perspect 2005; 19:107-130.

18 Deev PA, Shestov MD, Abernathy PJ, Kapustina MA, Muhina MN, Irving MS: Association of alcohol consumption to mortality in middle-aged U.S. and Russian men and women. Ann Epidemiol 1998;8:147-153.

19 Cockerham WC, Snead CM, DeWaal DF: Health lifestyles in Russia and the socialist heritage. J Health Soc Behav 2002;43:42-55.

20 Hinote BP, Cockerham WC, Abbott P: The specter of post-communism: women and alcohol in eight post-Soviet states. Soc Sci Med 2009;68:1254-1262.

21 Khaltourina DA, Korotayev AV: Potential for alcohol policy to decrease the mortality crisis in Russia. Eval Health Prof 2008;31:272281.

22 Christian D: Living Water: Vodka and Russian Society on the Eve of Emancipation. Oxford, Clarendon, 1990.

23 Abbott P, Wallace C: Talking about health and well-being in post-soviet Ukraine and Russia. J Communist Stud Transit Polit 2007; 23:181-202.
24 Russian Longitudinal Monitoring Survey; conducted by the Higher School of Economics and ZAO 'Demoscope' together with the Carolina Population Center, University of North Carolina at Chapel Hill and the Institute of Sociology RAS. http://www.cpc.unc. edu/projects/rlms-hse, http://www.hse.ru/ org/hse/rlms (accessed July 14, 2012).

25 Britton A, McKee M: The relation between alcohol and cardiovascular disease in Eastern Europe: explaining the paradox. J Epidemiol Community Health 2000;54:328-332.

26 Klatsky AL, Armstrong MA: Red wine, white wine, liquor, beer, and risk for coronary artery disease hospitalization. Am J Cardiol 1997;80:416-420.

27 Vallin J, Meslé F: Mortality in Europe: the divergence between East and West. Population 2002;57:157-198.

28 Nicholson A, Bobak M, Murphy M, Rose R, Marmot M: Alcohol consumption and increased mortality in Russian men and women: a cohort study based on the mortality of relatives. Bull World Health Organ 2005;83: 812-819.

29 Holmila M, Raitasalo K: Gender differences in drinking: why do they still exist? Addiction 2005; 100:1763-1769.

30 Monteiro MG: A World Health Organization perspective on alcohol and illicit drug use and health. Eur Addict Res 2001;7:98-103.

31 Watson P: Explaining rising mortality among men in Eastern Europe. Soc Sci Med 1995;41:923-934.

-32 Nemtsov A: Alcohol consumption in Russia: is monitoring health conditions in the Russian Federation (RLMS) trustworthy? Addiction 2004;99:386-387.

33 Källmén H, Wennberg P, Berman AH, Bergman H: Alcohol habits in Sweden during 1997-2009 with particular focus on 2005 and 2009, assessed with the AUDIT: a repeated cross-national study. Eur Addict Res 2011;17: 90-96.

-34 Van Gundy K, Schieman S, Kelly MS, Rebellon CJ: Gender role orientations and alcohol use among Moscow and Toronto adults. Soc Sci Med 2005;61:2317-2330. 